3. Masjuan J, Arenillas J, López-Fernández JC, Calleja S. Unidades de ictus: el mejor tratamiento para los pacientes con ictus. Med Intensiva. 2009;33:407.

4. Hess DC, Wang S, Hamilton W, Lee S, Pardue C, Waller JL, et al. Clinical feasibility of a rural telestroke network. Stroke. 2005;36:2018-20.

5. Chalela JA, Kasner SE, Jauch EC, Pancioli AM. Safety of air medical transportation after tissue plasminogen activator administration in acute ischemic stroke. Stroke. 1999;30: 2366-8.

\section{Donantes tipo III de Maastricht}

\section{Maastricht type III donors}

\section{Sr. Director:}

Leímos con mucho interés la carta al director de la Dra. Corral et al. ${ }^{1}$ referente al primer caso de donación tipo III de Maastricht, con canulación ante-mortem de arteria y vena femorales para perfusión, descrito en nuestro país.

Coincidimos con los autores en que para ampliar las posibilidades de donación es fundamental optimizar la calidad de los protocolos existentes y buscar nuevas líneas de trabajo. Entre ellas, la donación tipo III de Maastricht o donantes a corazón parado controlados (DCPC) ${ }^{2}$. Esta podría ser una alternativa válida más, como lo es en otros países ${ }^{3}$.

En esa línea de pensamiento, nuestro hospital comenzó en el año 2005 un programa de donación en asistolia «no controlada» extrahospitalaria (en colaboración con el servicio de atención extrahospitalaria SUMMA 112 de nuestra comunidad autónoma) y de asistolia «controlada» intrahospitalaria.

Desde su inicio y hasta diciembre de 2010, el programa ha conseguido completar con éxito 155 trasplantes renales, 46 hepáticos y 1 bipulmonar, gracias a los órganos obtenidos por esta vía; lo que ha supuesto un $13 \%$ de la totalidad de los trasplantes realizados en nuestro centro.

Para llevar a cabo dicho programa, contamos con un protocolo de actuación, consensuado con el SUMMA 112, los diversos servicios intrahospitalarios que participan en este procedimiento y la Coordinación de Trasplantes. En el mismo se contempla, tras la certificación de la muerte por asistolia del individuo, el reinicio de las maniobras de masaje cardiaco y ventilación hasta la canulación arterial y venosa para el inicio de circulación extracorpórea, limitada al territorio abdominal, con un oxigenador de membrana, llevado a cabo por el equipo de perfusionistas de nuestro centro.

Tras revisar el protocolo de actuación de la Dra. Corral et al. ${ }^{1}$, decidimos adecuarlo a nuestras posibilidades y aplicarlo en uno de nuestros casos, tras consensuarlo con nuestro equipo de coordinación hospitalaria.

Se trata de una paciente con daño cerebral grave e irreversible sin perspectiva de evolución a muerte encefálica en el que, junto con la familia, se decidió la limitación de tratamiento de soporte vital (LTSV). Tras la decisión consensuada de LTSV se planteó a la familia, que aceptó, la posibilidad de donación tras el paro circulatorio, con consentimiento de
L.J. Rodríguez Martín*, J.M. Gutiérrez Rubio,

J.I. Garrote Moreno y P. Crespo Velasco

Helicóptero Sanitario de Cuenca, Helicópteros INAER, Cuenca, España

* Autor para correspondencia.

Correo electrónico: ljrm.111@gmail.com

(L.J. Rodríguez Martín).

doi:10.1016/j.medin.2011.05.019

canulación ante-mortem de arteria y vena femorales para perfusión precoz de los órganos.

Para ello trasladamos a la paciente al quirófano, donde se procedió a la canulación arterial y venosa femoral para la circulación extracorpórea limitada a los territorios mencionados. Una vez realizada, se procedió a la desconexión terminal hasta el paro circulatorio, que se produjo tras 14 minutos. Tras certificar el éxitus por parada circulatoria durante 5 minutos, según nuestro protocolo de donación, se procedió a la conexión a circulación extracorpórea limitada. La extracción renal y hepática se llevaron a cabo sin problemas, siendo exitoso el seguimiento de los órganos trasplantados; con evidencia de un periodo de oligoanuria muy corto, respecto a la donación en asistolia «clásica»; y un buen funcionamiento hepático en el postoperatorio inmediato. No se planteó la extracción pulmonar en este caso por no cumplirse en la donante los criterios aceptados en nuestro protocolo hospitalario para este procedimiento.

Coincidimos con la Dra. Corral et al. ${ }^{1,4}$ en que este tipo de procedimiento, siempre que se lleve a cabo en hospitales seleccionados, con los protocolos y la información adecuados y con el seguimiento de la ONT, no debería afectar negativamente a la excelente acogida que los programas de trasplante tienen en España, cuyo modelo es referencia mundial.

Es importante recalcar que la decisión de LTSV es previa al planteamiento de donación de órganos y que en ningún caso puede ser la justificación de la misma. En nuestro Servicio de Medicina Intensiva del Hospital Universitario 12 de Octubre, trabajamos desde hace años con un protocolo de LTSV y de cuidados del paciente al final de la vida, consensuado por médicos y enfermería, y con la aprobación del Comité de Ética Asistencial de nuestro hospital; basado en las recomendaciones publicadas por el Grupo de Bioética de la SEMICYUC 5 .

Una vez decidida la limitación, y tras la información y consenso de todo el personal implicado, el equipo de coordinación de trasplantes procederá a la solicitud de donación en asistolia, con la información familiar completa acerca del procedimiento.

\section{Bibliografía}

1. Corral E, Maynar J, Saralegui I, Manzano A. Donantes a corazón parado tipo III de Maastricht: una opción real. Med Intensiva. 2011;35:59-60. 
2. Koostra G. Statements on non-heart-beating donor programs. Transplant Proc. 1995;27:2965.

3. Reich DJ, Mulligan DC, Abt PL, Pruett TL, Abecassis MM, D'Alessandro A, et al. ASTS recommended practice guidelines for controlled donation after cardiac death organ procurement and transplantation. Am J Transplant. 2009;9:2004-11.

4. Del Río F, Escalante JL, Núñez JR, Calvo E. Donación tras la muerte cardiaca. Parada cardiaca en el mantenimiento del donante en muerte encefálica. Med Intensiva. 2009;33: 327-35.

5. Monzon JL, Saralegui I, Abizanda I, Campos SA, Cabré L, Iribarren S, et al. Recomendaciones de tratamiento al final de la vida del paciente crítico Grupo de Bioética de SEMIYUC. Med Intensiva. 2008;32:121-33.
J.A. Sanchez-Izquierdo Riera ${ }^{a, *}$, C. Cisneros Alonso ${ }^{a}$, R. García Guijorro ${ }^{\text {, J.C. Montejo González }}{ }^{a}$ y A. Andrés Belmonte ${ }^{b}$

a Servicio de Medicina Intensiva, Hospital Universitario 12 de Octubre, Madrid, España

${ }^{\mathrm{b}}$ Coordinador de Trasplantes, Hospital Universitario 12 de Octubre, Madrid, España

* Autor para correspondencia.

Correo electrónico: jasir@saludalia.com (J.A. Sanchez-Izquierdo Riera).

doi:10.1016/j.medin.2011.06.001 